statement, and this with some self-satisfaction to me as a foreign graduate in opposition to a graduate from Barnes Medical College at St. Louis ("Polk's Directory"). Every learned European and German, not even necessarily a physician, knows and admits that some of the American schools are fully equal to the European standard, that a large number of American physicians, living and dead, are found among the leaders in the profession, and full credit is given to what Americans have done for the advancement of science. The question of equivalence, however, does not come up at all in legislating for the regulation of licensed practice of medicine ; compare the State of New York, etc.

B. BECKER, M.D.

\section{An Interesting Case.}

Sioux Falls, S. DaK., Dec. 27, 1897.

To the Editor:-Christmas eve two men engaged in a quarrel in a saloon in this city over a bill. They went out into the street to continue the quarrel. After some words, the larger of the two, who was a large powerful man, struck the other a severe blow in the mouth. Instead of falling backward as would have been expected, the man hit fell forward and his enemy struck him another blow as he went down. He immediately became unconscious, and though his heart was beating when medical aid reached him, respiration had ceased and he was shortly pronounced dead.

All sorts of conjectures were indulged in as to the probable cause of death, it not being thought probable that two such blows as were given could kill a man. Some attributed it to heart disease, others thought his neck must have been broken. The autopsy disclosed the fact that the man when struck had a large quid of tobacco in his mouth and had probably at the instant of receiving the blow taken a sudden and deep inspiration, drawing the tobacco down deep into the larger bronchi, completely occluding them, causing his almost instant death.

The coroner's jury found the man who struck the blows guilty of manslaughter in the second degree. We have heard of tobacco causing death, but never before in just this way.

A. H. Tufts, M.D.

\section{Medical Courtesy.}

Clarksburg, W. Va., Dec. 21, 1897.

To the Editor:-In case a physician who is in good standing in his State medical society moves his location to a town in a neighboring county of the same State, in accordance with social or professional ethics, who is expected to first extend courtesies in the way of friendly calls, the new-comer or his older established professional brethren?

Very respectfully,

R. A. H., M.D.

ANSwER: Where a physician moves into a neighborhood, courtesy demande that his brother practitioners should call on him within a reasonable time and give him the right hand of fellowship.

\section{Texas Medical Practice Laws.}

Chicago, Dec. 28, 1897.

To the Editor:-Kindly advise me in our Journal as to law and regulations of practicing medicine in the State of Texas.

"Doctor."

Answer : A license is iseued after examination by a District Board of Medical Examiners. Diplomas confer no right to practice. Tide the JournaL, Vol. 22 , p. 355 .

\section{SOCIETY NEWS.}

Therapeutic Society.-At a meeting held at the National Med. ical College, July 29, 1897, to organize "The Therapeutic Society of the District of Columbia," there were present, Drs. H. H. Barker, G. R. L. Cole, C. T. Caldwell, J. T. Kelley, Jr., L. Kolopinski, D. O. Leech, J. S. McLain, G. C. Ober, W. M.
Sprigg, M. F. Thompson, J. T. Wintern, The following offi cers were elected : L. Kolopinski, president; J. T. Winter, first vice-president; W. M. Sprigg, second vice-president; J. T. Kelley, recording secretary; G. C. Ober, corresponding secretary; J. S. McLain, treasurer. Article II of the constitution says, "The object of the Society shall be the study and advancement of medical and surgical therapeutics in all of the special branches of practical medicine. The Society meets in one of the rooms of the National Medical College, on the second Saturday of each month. The active membership is lim ited to fifty, and any member of the Medical Association of the District of Columbia is eligible."

J. Thomas Kelley, Recording Secretary.

St. Louis Laryngological and Otological Society.-On December 27 the St. Louis Laryngological and Otological Society was formed, composed of those physicians of St. Louis who limit their practice to the treatment of diseases of the nose, throat and ear. Dr. J. C. Mulhall was elected president; Dr. J. B. Shapleigh, vice-president; Dr. F. M. Rumbold, secretary, and Dr. A. S. Barnes, Jr., treasurer ; for the year 1898. Meetings will be held monthly, and it is expected that the scientific programs furnished will be highly interesting and instructive. While the membership is limited, the privilege of inviting professional friends is reserved to each member.

\section{BOOK NOTICES.}

Transactions of the Medical Society of New Jersey. Cloth. Pages 347. 1897.

This volume covers the one hundred and thirty-first annual meeting held at Atlantic City, N. J., June 22 and 23, 1897. Besides society data it contains the following papers: "The Value of Antitoxin as a Remedial Agent . . Against Diphtheria ;" "Present Status of the Serum Treatment of Diphtheria ;" "Headaches; Auto-intoxication a Factor ;" "A Criticism of Modified Milk and of Modern Dairy Methods ;" "Some Important Points in . . . Acute Lobar Pneumonia;" "Scarlet Fever Reproduced by Inoculation . . . . ;" "Progress in State Medicine and Hygiene ;" "Aphorisms on MedicoLegal Testimony ;" "Progress in Bacteriology During the Past Year ;" "Progress of Ophthalmology and Otology ;" "Account of a Patient . . . Who Swallowed Numerous Indigestible Articles with Suicidal Intent."

Transactions of the Medical Society of New Jersey. Cloth. Pages 453. 1896.

This volume contains full proceedings of the one hundred and thirtieth annual meeting held at Asbury Park, N. J., June 23 and 24,1896 . The paper and press work of the volume are a credit to the society, the volume being a companion volume to that for 1897. The contents comprises reports, minutes, etc., and a number of valuable papers.

The Action of the Health Department in Relation to Pulmonary Tuberculosis and the Scope and Purpose of the Measures Recently Adopted for its Prevention. Paper. Pages 70. 1897.

This is a report of the Board of Health of New York City, made to Mayor Strong, and contains much valuable data concerning pulmonary tuberculosis. Several maps of New York wards add to its value.

Proceedings of the Ninth Annual Session of the Association of American Anatomists. Paper. Illustrated. Pages, 65. Washington, 1897.

The volume contains the proceedings of the annual meeting held in Washington, D. C., May 4-6, 1897, including papers presented at the meeting and a number of full page half-tones illustrating the papers.

Biennial Report of the Department of Health of the City of Chicago being for the years 1895 and $1896 . \quad$ Chicago. 1897.

This report is one of the most valuable ever published by the Health Department. Dr. Reynolds in his letter of trans- 